\title{
Professional education for digital economy: trends and prospects
}

\author{
Dmitry Barsukov ${ }^{1}$, Svetlana Kuzmina ${ }^{1, *}$, Natalia Morozova $^{2}$, and Anna Pimenova ${ }^{3}$ \\ ${ }^{1}$ Saint-Petersburg State Institute of Film and Television, 13, Pravda str., Saint-Petersburg, Russia \\ ${ }^{2}$ Saint-Petersburg State Forest Technical University, 5, Institutskiy per., Saint-Petersburg, Russia \\ ${ }^{3}$ Saint-Petersburg State University of Economics, 21, Sadovaya str., Saint-Petersburg, Russia
}

\begin{abstract}
In the present article, the crucial and specific aims of teaching that provide an ample staff competence for digital economics are introduced. We investigate contemporary teaching and training approaches, trends in staff quality requirements. The article highlights new employment trends and values that have been formed recently in environmental, technological and consumer services as a result of digital, creativity and virtual processes in business increased. We used comparison methods, analysis, observations with consequential conclusions for this survey. It should be noted that information literacy, attentional and emotional control skills, creativeness, ecological and intercultural mindedness, ability to be re-educated are clues for each career. We suppose that the implementation of best international and European teaching methods and standards and prompt introduction of new educational programmes into Russian educational system are key solutions that could provide graduates with expected competencies.
\end{abstract}

\section{Introduction}

The analysis of contemporary economics' digital transformation trends and revealing relevant professional competencies that should be consider in educational programmes are the aims of this study. The problems of educational programmes' changes accordingly with economics' digitalization, state's social and economic level, digital transformation modelling opportunities, contemporary professional competencies and professional building skills were revealed by known authors. It worth to refer proceedings of Okrepilov V. [1], Evmenov A., [2], Widdeth S. and Holliford S. [3], Meister [4], Parkinson [5]. Creative economy, ecology and environmental economy, human - oriented services are well-known spheres of business nowadays. They are based on human creativeness and demand certain personal and professional skills and qualities, which weren't so important previously.

\section{Research methodology and statistics}

\footnotetext{
${ }^{*}$ Corresponding author: kuzmina2003@bk.ru
} 
We used analysis and synthesis of available statistic data as well as comparison and juxtaposition these data, subsequent interpretation and conclusions. We suggested that personnel education system features could be described with the analysis of general qualitative trends in economy and economic statistic data.

From our point of view, the following tendencies are essential for world economy nowadays:

- employment decrease (approximately by $50 \%$ during next 20 years);

- staff re-education and postgraduate education in accordance with digital economy demands;

- social guarantees reduction (for instance, reduction of pension and medical plans, long- term labour contracts, vocational guidance).

All these facts seem to be consequences of the global trends in world economy, which were disclosed in the report "Skills of the future. What you need to know and be able to do in a new complex world" [5]. According to the report's authors the essential changes are being expected in employment sphere and professional education during medium term period. Despite these facts the prospects for employment growth in certain economy branches such as creative economy, digital and virtual economy, environment recovery and human oriented services are obvious.

Experts expect the employment growth at these economy sectors, so they predict that the demand for professional personnel will be increased too. Professional qualities and competencies will be focused on development the human creativity. The skills used for physical and intellectual routine procedures will not be actual. The teaching methods and instruments will be more and more close to the approaches that use for creative industry's personnel. Consequently, the whole professional education system will be forced to meet new expectations. The project FutureSkills is social movement in frame of which business and state join facilities to produce so called "personnel of future". As the elements of the project they introduce the international education and training standards into national professional education system, carry out upgrading of pedagogical staff qualification.

To illustrate actual problems and trends of the national professional education system it's worth to describe the specific details of competencies building in frame of professional educational programmes for creative industries. Creative industries are spheres that based on personal creativity, natural aptitude and talent. They create added value and job opportunities through the manufacturing and exploitation of intellectual property [6]. The feature of creative industry is that it includes the activity in many different spheres. On one hand, creative industry produces cultural values, on the other - they are commercial enterprises focused of a real commercial profit. The creative industries nowadays include fashion industry; design, decorative arts and handicrafts; advertising; architecture; visual arts; performing arts and entertainments; creation pieces of music and sound recordings; cultural tourism and museum activities; publishing; creation of films and video products; creation of television and radio programs, including Internet products; creation of computer games and multimedia.

Nowadays creative industry is influenced by many factors. As concerns the Russian creative industry it is obvious that we have exceptional and diverse cultural resources. However, the potential has not been realized in past years. According to the statistical data the export share of Russian industries based on copyright is only $0,49 \%$. In comparison with China's 18,29\%, Italy's 7,61\% and Great Britain's 5.67\% this indicator is very and very low. The result of Indonesia is about $0,89 \%$. This is twice as much as that of Russia.

The crucial features of Russian creative economic sectors are affected by certain aspects that include the cluster model of evolution, everyday balance between innovations and risks, and in addition, the profitability and effectiveness of projects usually hardly taken into consideration. 
The cluster model of Russian creativity industry means developing that sphere and projects at some regions or even the parts of cities at the time of poor cultural life in others. The rapidly growing clusters in culture (centers of contemporary arts, cultural heritage projects and etc.) turn up in big Russian cities including Moscow and Saint Petersburg. The reasons include different level of cultural heritage in regions, differences in educational and cultural development of regions, differences in government support and fuds that could be spent on cultural projects. The balance between innovations and risks is coursed by administrative and economic barriers, and by political reasons and sometimes even by censorship. The low level of culture managers' practice experiences, shortcomings of their professional education, even the lack of professional managers in creative business are seemed the reasons of faults in projects' profitability and commercial effectiveness. As a result, Russian creative industry functions in the circumstances of infrastructure problems and low interaction between cultural and business targets.

The efforts to correct the situation should cover digitalization processes of economy, boosting tourism (as we have already unique historical and cultural heritage basis), smart urban environment and certain cultural projects. They should be basis for territories and region development in the circumstances of limited recourse and funds for creative industry.

However, thinking about creative industry prospects we need to take into consideration that it's an extremely demanding job. In other words, creative industry professionals are facing specific demands to the competencies, skills, attainments, experience and knowledge. These demands should be put into the basis of contemporary professional education. In addition, the digital and creative trends of global economy development prescribe to set this demands relevant not only for the creative industry, but also for a significant number of other branches of economy.

\section{Results}

Based on crucial professional education trends analysis and on demands concerning new staff competencies we can made conclusions about "working place of 21 century" model. It includes the number of essential elements.

Firstly, technological aspects: digitalization of all spheres of life is the real fact of life. It is accompanied by the scaling up and spreading of internet resources and facilities, of digital data forms.

Secondly, techno-social aspects: world's globalization and world's greening. Interconnection in economy, technology and culture become more and more closer. Manufacturing chains, consuming goods, scientific research, cultural codes, they all mostly international today. The fact is that international products succeeded. On the other hand, greening influences consuming, manufacturing, business processes and minds as well.

Thirdly, social aspects include demographic and so call "network society" trends. The growth of life expectancy, of woman's role in the economy, scaled urbanization processes, changes in childhood model - all this tendencies influence on contemporary social scenario.

Finally, the "meta trend" concerns the fact that all changes mentioned above are by the influence of one tendency - the increasing speed of changes.

The influence of the trends could be felt in all levels of life. Instruments, materials, manufacturing logistics change. As a result, the whole system of working places is changing, including qualities, skills and knowledge demands, as well as demands concerning the professional education system.

The clue result of the research is a conclusion that all mentioned above trends should be considered in new professional education programmes, postgraduate programmes and 
should be introduced through new competencies of graduates in accordance of digital economy demands.

On the other hand, the professional education system is tightly controlled by government. Today we have educational low, educational standards and concepts. The basis of national professional education is concentrated in the Federal Low "On education in Russian Federation" [8]. It introduced the structure of national education system, the requirements for professional educational standards, for the forms of professional education, for the methodological and for resources approaches.

In terms of contemporary professional education system development, the essential question is how to create theoretical and methodological basis to prepare young individuals for the world of work to make them be ready to meet requirements of digital economy. Speaking about professionals for creative industries, for instance, let us look at producers' professional qualities. The crucial professional attributes are a kind of merger between creativity and commercial skills. To be a successful producer individual need to be successful director, marketing expert and administrator. In addition, it is essential to have high level digital literacy. As a result, education programmes for future producers should include the theory and the practice of project management, the theory of culture policy, intangible assets management, intellectual product commercialization, information and communication technologies.

\section{Discussions}

Thoughts we described above also lead to the conclusion that certain theoretical and methodological basis as well as certain teaching instruments and techniques should be worked out to develop creativeness of graduates $[9,10]$. This crucial personal quality tends to be professional quality of the staff for digital economy. According to the 1 -st article of federal educational law [8], among basic principles of education were announced unobstructed personality development and creation conditions for personal fulfilment.

We assume that the content of contemporary professional educational programmes has to spread the humanitarian and aesthetic values as well as commercial skills and experience to promote creative and humanitarian ideas into world of consumption.

On the other hand, we think that it is essential to change the methods of professional education to meet the expectation of employers regarding digital literacy and creativity skills. The logic of methods should include teaching without standard and ordinary tasks, students emotional involving, team working, competitiveness atmosphere, environmentally friendly attitude.

Practice oriented tasks with elements of real work situations, interdisciplinary projects that motivate students to apply the theoretical knowledges to a real business problem are most effective way to stimulate interest and to obtain best result.

The tasks that have solutions lying in interdisciplinary area stimulate students interest most of all. They encourage students to work in team. Very often it is impossible for creative industry to produce the result without team working. Intangibles asset could be produced by individual who are the author of idea, text, scenario, music or art masterpiece. But usually technologist or engineer is a person who incarnate the idea. Finally, a market expert helps to sell the result. And in addition, the manager organises the whole production process and supports the logic and sequence of all team work. That is the team work and students have to get ready to succeed in it to be competitive professional.

The question about competencies evaluation criteria occurs in each stage of professional life, including hiring, working period, dismissal. It is essential for an employer to have measurable indicators of staff competencies level to be able to make effective solutions and evaluate professional skills of an employee [12-18]. 
In addition, it seems to be important to consider the classification of companies. We suggest that companies used digital technologies could be divided on three groups. First group includes those that are on initial level of digital technologies. The other companies they are developing with different pace. They are having got more or less difficulties with digitalization. Finally, the third group includes major companies, generally with turnover more than 1 bln USD and located in 16 developed countries. We can define them as a "leaders" as they combine high level of digitalization and effective managerial approaches. Specialists call them "Digirati" and point out that they have undeniable competitive advantages in their fields of activity. From the point of building key business processes, digital business transformation allows to transform operational processes to get significant competitive favorable position in management, manufacturing and motivation of employees. Digerati have reoriented managerial efforts to strategic aims, turning employees to the strategic way of thinking, motivate them to concentrate on research, rather than routine operations.

\section{Conclusions}

To sum up the results of analysis the certain features of professional education for digital economy and crucial trends of international digitalization development we'd like to highlight some main thoughts. It's essential to enforce the projects that effect on digital economy, digitalization of business activity, development in tourism sphere, fair, exhibition and congress activities, "smart" urban social medium, commercializing cultural heritage as well. Digitalization progress should be based on cluster approach. Information technologies are the basis not only for a business activity but allows to reproduce the cultural heritage and customs in a contemporary way.

Professional education in accordance with the digital economy demands is a serious area for research and improvements. We need to provide graduates with certain set of new skills and proficiency. But we need to create a new logic of education model to make graduates succeeded in irregular business processes and competitive business environment, to be environmentally conscious and successful in team working. These are strategic aims for whole education system, including primary, secondary and professional elements of the system.

\section{References}

1. V.V. Okrepilov, S.N. Kuzmina, V.L. Makarov, A.R. Bakhtizin, Economy of Region 2, 301-313 (2015)

2. A.D. Evmenov, P.A. Bulochnikov, I.Yu. Blagov, Journal of Legal and Economic Studies 4, 203-210 (2013)

3. S. Widdet, S.M. Hollifford, HIPPO (2003)

4. D.M. Meister, Alpina Business Books (2004)

5. M.M. Parkinson, HIPPO, 22 (2003)

6. Skills of the future. What you need to know and be able to do in a new complex world. "Union "Young Professionals" (Worldskills, Russia) http://проф-обр.pф/board/21-1-0$\underline{1621}$

7. N.G. Fedotova, Cultural Review. Informational and analytical collection 2, 23-33 (2009) 
8. Federal Law 273-FZ of December $29 \quad$ (2012) http://www.consultant.ru/cons/cgi/online.cgi?req=doc\&base $=$ LAW\&n=292679\&fld=1 $\underline{34 \& d s t=1000000001,0 \& r n d=0.9102110769356158 \# 024047445137997236}$ Marketing research of the site development market in Russia 2012-2016, forecast up to 2021 (2018) https://marketing.rbc.ru/research/30164/

9. Federal state educational standards for secondary professional education. Access mode: http://xn--80abucjiibhv9a.xn-p1ai/\%D0\%B4\%D0\%BE\%D0\%BA\%D1\%83\% D0\%BC\% D0\%B5\%D0\%BD\%D1\%82\%D1\%8B/923

10. On approval of the list of indicators of the quality standard of budget services in the field of culture (2018) URL:http://docs.cntd.ru/document/473800064

11. Portal of Federal State Educational Standards. Post graduate education programs 2017 (2018) http://fgosvo.ru/pages/view/id/23

12. L. N. Nikolova, D. G. Rodionov, M.A.Bahauovna, International Journal of Economics and Financial 6(2), 246-252 (2016)

13. A. Mottaeva MATEC Web of Conferences, 106, 08071 (2017) https://doi.org/10.1051/matecconf/201710608071

14. A. Mottaeva, J. Ćetković, Advances in Intelligent Systems and Computing, vol 692 , pp. 1151-1159 (2018) doi.org/10.1007/978-3-319-70987-1_123

15. A. Mottaeva, IOP Conf. Series: Earth and Environmental Science 90, 012124 (2017) doi : 10.1088/1755-1315/90/1/012124

16. T. Tereshkina, A. Mottaeva, L. Andreeva, T. Larinina, IOP Conf. Series: Earth and Environmental Science 90, 012138, (2017) doi:10.1088/1755-1315/90/1/012138

17. A.Seleznev, A. Mottaeva, L. Andreeva, S. Izmaylova, IOP Conf. Series: Earth and Environmental Science 90, 012117, (2017) doi:10.1088/1755-1315/90/1/012117

18. G. Dyakova, S. Izmaylova, A. Mottaeva, E. Karanina, IOP Conf. Series: Earth and Environmental Science 90, 012218 (2017) doi:10.1088/1755-1315/90/1/012218 